\title{
O NEGRO BRASILEIRO E A SAÚDE - ONTEM, HOJE E AMANHÃ
}

Isabel Cristina Fonseca da Cruz*

CRUZ, I. C. F. da. O negro brasileiro e a saúde: ontem, hoje e amanhã. Rev. Esc. Enf. USP., v. 27, n. 3, p. 317-27, dez. 1993.

Este estudo tem por objetivo apresentar uma análise sobre o processo saúde-doença na etnia negra brasileira, desde o seu seqüestro na África até os dias atuais, apontando perspectivas futuras. Utilizou-se como fonte de dados a literatura e a Taxonomia I, de diagnósticos de enfermagem, para nomear as possiveis alteraçōes de respostas apresentadas pelos negros diante dos problemas de saúde/processo vital. Devido às condiçōes de miséria em que hoje se situa a maioria da raça negra brasileira e à diminuta quantidade de pesquisas na área de saúde referente a este grupo étnico, concluiu-se que é necessário criar urgentemente grupos de trabalho institucionais com a finalidade de promover o desenvolvimento social da população negra brasileira e de estudar as suas crenças, valores e práticas de saúde.

Unitermos: Afro-brasileiro, Negro, Diagnósticos de Enfermagem.

\section{INTRODUÇĀO}

Primeiramente, eu gostaria de agradecer à Coordenação do I Seminário Niteroiense sobre o Negro Ontem, Hoje e Amanhã, o convite para proferir esta palestra. Gostaria também de parabenizar pela realização deste evento o Grupo Consciência Negra, a União dos Grupos de Trabalho para o Desenvolvimento do Negro, o Grupo de Capoeira Modelo Cultural, Kikongo, o Centro de Estudos Africa-Brasil "Ironildes Rodrigues" e o Grupo de Pesquisa "João Cândido".

Antes de desenvolver o tema que me foi proposto, entendo ser importante prestar um rápido esclarecimento. Enquanto negra, enfermeira, professora e estudante, eu raríssimas vezes abordei teoricamente, dentro da área da saúde, questōes relativas a minha raça e cultura. Mesmo realizando consultas com clientes com Hipertensão Arterial,

Doutora em Enfermagem. Professora Assistente do Departamento de Enfermagem Médico-Cirúrgica da Escola de Enfermagem Anna Néry - UFRJ. Coordenadora do Núcleo de Consciència Negra na USP. 
doença freqüente entre negros, jamais cheguei a considerar a categoria raça uma categoria tão relevante, a ponto de dedicar-lhe estudos próprios.

Entretanto ao levantar a literatura profissional latino-americana (Index Medicus Latino Americano, Revista Brasileira de Enfermagem, Revista da Escola de Enfermagem da USP e Revista da Faculdade de Saúde Pública da USP), no período de 1985 a 1990, sobre o processo saúde-doença do negro, verifíquei que eu não era a única a não me preocupar com a questão da raça negra, visto que encontrei apenas um relato de pesquisa*. Ainda assim, esta pesquisa era sobre brancos descendentes de negros (SOUZA et al, 1987).

Ainda que essa revisão da literatura não tenha sido suficientemente exaustiva, pude perceber que o que existe na área da saúde sobre o negro, especificamente, é muito pouco ou está diluído em trabalhos com temáticas diversas, nos quais a cor é apenas uma referência não analisada.

A constatação da escassez de estudos científicos sobre a saúde e a doença do negro causou-me uma profunda perplexidade. Vejo agora com clareza a força e a permanência da ideologia da escravidão pois, consegue nos tempos atuais fazer com que os profissionais da saúde ignorem, na prática, as categorias presentes nos discursos: individualidade, raça, grupo étnico e cultura.

Esta ausência do negro nas pesquisas e documentos oficiais é discutida muito apropriadamente por SKIDMORE (1991) que credita este fenômeno às teses assimilacionistas e à ideologia do branqueamento.

Diante da escassez de estudos sobre etnia negra na área da Saúde, desenvolvi o tema com a ajuda de textos da área de História e Ciências Sociais dentro de uma perspectiva de Enfermagem. Portanto, tratarei não das doenças, pois estas são por tradição objeto da Medicina, no meu entender.

Abordarei neste estudo o que considero ser a contribuição específicaı de enfermagem às ciências da saúde, a saber: diagnosticar e tratar as respostas do indivíduo ao processo saúde-doença. Estas respostas correspondem aos diagnósticos de enfermagem nomeados, neste estudo, segundo a Taxonomia I da North American Nursing Diagnosis Association NANDA (CRUZ, 1990; NORTH AMERICAN NURSING DIAGNOSIS ASSOCLATION, 1990; FARIAS et al, 1990, CRUZ; CRUZ, 1991).

Cabe observar que os diagnósticos apresentados neste estudo só podem ser caracterizados como possíveis, ou seja, partem da inferência do profissional e não possuem uma forte base de dados significativos,

\footnotetext{
No momento em que realizo a revisão deste trabalho para publicaçáo devo observar que em levantamento bibliográfico realizado por meio do CD-ROM, na base de dados LILACS, compreendendo o periodo de $1983-93$, encontrei 36 referências brasileiras. A maioria delas encontra-se nas seguintes áreas: genética, anatomia e hemotologia. Entendo ser necessário este esclarecimento, mas diante da natureza dos trabalhos encontrados reafirmo as posiçóes apresentadas neste estudo quanto ao desconhecimento sobre o processo saúde-doença nas pessoas de etnia negra.
} 
indicando a necessidade de aprofundamento das investigaçōes, enfim, do histórico de enfermagem (CARPENITO, 1987). Neste estudo, os diagnósticos são possíveis porque constituem, em princípio, uma especulação com base nos dados literários e na experiência da autora.

\section{DESENVOLVIMENTO}

\section{O processo saúde-doença}

Saúde é um conceito abrangente e subjetivo, varia de indivíduo para indivíduo, de região para região e de cultura para cultura. Podemos dizer que à saúde contrapōe-se a doença, formando ambas um processo contínuo, no qual as pessoas movem-se continuamente. Entretanto, tanto saúde quanto doença constituem fenômenos que possuem múltiplas causas de natureza física, mental, espiritual, social e política (IDE; CHAVES, 1990).

Um aspecto determinante - de interesse para este estudo - refere-se ao significado de saúde que as pessoas das classes camponesas e de operariado urbano possuem, associando-a à capacidade de trabalhar e à ausência de doença (MURARO, 1983).

Partindo desta idéia de que a percepção das pessoas trabalhadoras sobre o processo saúde-doença tem uma íntima ligação com o trabalho, analisarei a saúde do negro tendo em vista a sua inserção no sistema produtivo capitalista.

Segundo IDE; CHAVES (1990) a análise sociológica do processo saúde-doença é uma alternativa mais abrangente e complexa que a análise baseada no modelo biológico. A saúde-doença, pela vertente sociológica, resulta da relação entre o ser humano, historicamente situado, com uma função específica no sistema de produção, além da inserçāo no meio natural e social.

Concordamos com TOMAZI (1986) quando diz que:

"As causas determinantes da saúde e da doença coletiva são, em termos gerais, as maneiras como o homem entra em contato com a natureza, isto é, como se apropria dela e como, nesse processo a transforma. O processo saúde-doença é um fenômeno eminentemente social $e$ mutável, cujas manifestaçōes dependem direta ou indiretamente da estrutura social. As diferenças observadas entre as classes sociais na maneira de adoecer e morrer têm, em última instância, pouco a ver com os serviços médicos instalados e muita relaçāo com a organização da sociedade e com o papel que cada classe desempenha nela. "(p. 32)

A abrangência do conceito de saúde é, principalmente, resultado das formas de organização social da produção e da conseqüente estrutura de classes. 
No século XVII, deu-se início a grande importaçāo de negros para trabalhar no Brasil, cultivando a cana de açúcar. No século seguinte, com o advento da mineração, aconteceu um novo afluxo de africanos (QUEIRÓZ, 1987; MOURA, 1989).

O negro que vivia na África num sistema sem classes, comunitárioprimitivo foi submetido no novo continente a uma formação capitalista monopolista, para a qual contribuiria com o seu trabalho compulsório, melhor dizendo, com seu trabalho escravo.

O sistema capitalista criou uma supra estrutura ideológica e jurídica forte o bastante para manter o negro africano na condição de escravo, de instrumento de trabalho falante. Afinal, transformar um ser humano em escravo, em objeto, esvaziando-o de seu ser, de sua cultura e lembranças não é uma tarefa simples pois o humano existente no escravo predomina e dificulta as tentativas de coisificar a sua existência social e econômica (CARDOSO et al, 1988; SILVA, 1988; LOPES et al, 1987).

As conseqüências que o capitalismo escravocrata imprimiu na saúde da raça negra (tanto nos que foram escravizados, assim como nos que permaneceram na África) e na sua descendência podem ser reduzidas a pelo menos uma palavra: miséria. Esta condição sócio-econômica determinou e ainda determina sérios agravos à saúde dessa população. Não há paralelo nem com o holocausto judeu. No meu entendimento, o povo nativo das Américas vive também esta sistemática dizimação.

Segundo QUEIROZ (1987), os estudiosos de História consideram que, nos quatro séculos de escravidão, as Américas receberam 10 milhões de cativos. A agressão deliberada a saúde do negro iniciava-se já na própria África onde, expropriado de sua condição humana, era caçado e aprisionado (PINSKY, 1988). Penso eu que a saúde mental de nossos ancestrais africanos foi a primeira a se deteriorar quando estes perderam sua liberdade. $O$ aprisionamento e a expatriação provavelmente devem ter provocado uma forte angústia espiritual (NORTH AMERICAN NURSING DIAGNOSIS ASSOCIATION, 1989), em razão da quebra dos princípios que lhes regiam a existência.

As viagens nos navios negreiros ou tumbeiros (tumbeiros em razāo da quantidade de negros mortos na travessia para a América), após exaustivas caminhadas no continente africano até os portos, podem ser responsabilizadas por problemas de saúde de toda ordem (CHIAVENATO, 1987). Neste estudo, as alteraçōes que ocorrem nos padrões de respostas humanas diante dos problemas de saúde/processos de vida são expressas pelos diagnósticos de enfermagem (CRUZ; CRUZ, 1991).

As possíveis alterações individuais dos padrōes de respostas do negro - diagnósticos de enfermagem, naquele contexto, eram: alteração na nutriçāo, menos que as necessidades corporais; potencial para infecção, hipotermia, hipertermia, constipação, diarréia, déficit no volume de liquidos circulantes, troca gasosa ineficaz, limpeza ineficaz de vias aé- 
reas, padrão respiratório ineficaz, prejuizo da integridade tecidual $e$ alteração na mucosa oral (MOURA, 1989; NORTH AMERICAN NURSING DIAGNOSIS ASSOCIATION, 1989). Estes diagnósticos de enfermagem são referentes aos sistemas de controle do corpo e de permuta com o meio físico.

O contato abrupto entre europeus e negros e entre negros e negros de dialetos diferentes alterou o padrão de expressão, causando um prejuízo na comunicação verbal. Por sua vez, a capacidade de estabelecimento de vínculos com os seus semelhantes também estava comprometida $\mathrm{e}$ manifestava-se pelo prejuizo na interação social, pelo isolamento social e pela alteração no seu padrão sexual. A angústia espiritual evidencia a qualidade do julgamento sobre o significado e a importância daquela situação vivida.

Naquelas condiçōes de sofrimento e tortura, o negro tinha comprometida a sua capacidade de escolha, ou seja, de selecionar alternativas viáveis para tirá-lo daquela situação. Não obstante a sua disposição para a luta há que se considerar os instrumentos de força física e ideológica utilizados para mantê-lo submisso (SILVA, 1988; FREITAS, 1988; MOU. RA, 1989).

Nos meses que duravam as viagens nos tumbeiros, o negro estava impedido, por questōes de espaço ou de força, de movimentar-se. A grande quantidade de escravos transportados causava prejuizo da mobilidade física, fadiga e distúrbio no padrão de sono. As mães, dadas as condições, apresentavam um aleitamento ineficaz e as crianças tinham alteração no seu crescimento e desenvolvimento (MOURA, 1989).

Diante da subjugação do negro, através da coaçāo física e da ideologia da escravidāo, altera-se seu processo de percepção, levando-o a distúrbios na auto-estima e na identidade pessoal. Surgem a desesperança e a impotência. A consciência da situação é quase que inteiramente emocional e manifesta-se pela dor, pelo luto ou banzo, pelo potencial para a violência auto-dirigida (suicídio) ou dirigida a outros (assassinatos), pela ansiedade e pelo medo.

A chegada ao novo continente, mais especificamente no Brasil, não minimizou as agressōes sistemáticas à integridade física e mental do negro. Os que conseguiram sobreviver a travessia oceânica nos navios tumbeiros, ficavam em depósitos nos portos, expostos à visitação e inspeção públicas. A venda e a viagem até o local onde iriam trabalhar contribuíam ainda mais para a cronificação dos problemas de saúde já arrolados.

Pior do que o trabalho compulsório, só mesmo a tortura institucionalizada pelo capitalismo escravista. Trabalho e castigo na escravidão negra não se contrapunham; ao contrário, tornaram-se categorias indiferenciadas, ou seja, trabalho era castigo e vice-versa (LOPES et al, 1987; MOURA, 1989). Isto era real na carne dos negros e real na idéia dos escravocratas, tornando-se ao longo do tempo senso comum para toda sociedade brasileira, mesmo com o término formal da escravidão. 
Sobre as condiçōes de vida e saúde nos engenhos de açúcar, nas mineraçōes, nos cafezais, nas cidades e fazendas, pode-se afirmar, com base na literatura consultada, que eram de tal forma degradantes que a vida média de um escravo era de apenas sete anos (QUEIRÓZ, 1987). O negro era obrigado a trabalhar até mais de doze horas por dia, carregando consigo pesadas gargalheiras de ferro no pescoço e correntes nos pés (MOURA, 1989). E ainda me lembro que no primário aprendi que o negro foi escravizado, ao invés do nativo, por ser mais dócil e submisso ao trabalho.

Trabalhava na roça, sujeito às picadas de insetos e mordidas de cobras (potencial para envenenamento), ou entāo vinte e quatro horas por dia nos períodos de moagem da cana e refinamento do açúcar, causando fadiga extrema. Na mineraçāo, o escravo permanecia no garimpo dentro d'água por horas a fio ou nas insalubres minas subterrâneas. Nestas condiçōes não é difícil apresentar problemas de caráter respiratório, tais como: troca gasosa e limpeza de vias aéreas ineficazes. Ficava também o negro expos to a toda série de doenças transmissíveis e infecciosas, além, é claro, das ocupacionais, das hereditárias e das crônico-degenerativas.

Para enfrentar esta extenuante jornada de trabalho, o escravo recebia uma ração diária que estava aquém de suas necessidades corporais, tanto em qualidade de nutrientes, como em quantidade (MOURA, 1989; MAURO, 1991). Com uma nutrição deficitária, podia haver alteraçāo no crescimento e desenvolvimento das crianças adolescentes, alterafoóes na mucosa oral e pele, em decorrência de avitaminoses, e um déficit de líquidos circulantes, devido a uma hidratação insuficiente.

Após o seu dia de trabalho, o negro tinha como espaço para o repouso a senzala. Cabe ressaltar que o espaço do negro imposto pelo escravismo é sempre um espaço promíscuo, no qual ele não possuía condições de construir uma identidade pessoal, nem uma consciência social realmente positivas. No que se refere à saúde, a senzala era um ambiente propício para a disseminação de doenças, principalmente as respiratórias e de pele (MAURO, 1991). A convivência forçada, no mesmo espaço, de homens, mulheres e crianças, de diferentes idades e etnias deve, no meu entendimento, ter prejudicado num primeiro momento a interaçâo social. Superada esta barreira inicial, podemos depreender que aquele aglomerado de pessoas, vivendo numa pocilga, não compunham uma família pois, não possuíam laços de afetividade entre si.

O sexo não era expressão de amor e fonte de prazer pessoal, e sim um instrumento de reprodução do plantel do escravocrata. Se os homens eram reprodutores, as mulheres negras eram além de matrizes, objeto sexual do senhor. Es ta situação levava não só a uma alteração no padrão sexual do negro, como também ao desenvolvimento, nas mulheres, de síndrome pós-estupro e a uma alteração no papel de pai/mãe. Ser pai ou mãe para o escravo não tinha nenhuma relação com a transcendência e a continuidade do ser. Afinal, quem em são consciência desejaria ter um filho como escravo? Esta era talvez uma das razōes da alta freqüência do 
aborto, considerado pelos historiadores como uma forma de resistência passiva do negro (SILVA, 1988; PINSKY, 1988).

Nos domingos e dias santos, o negro trabalhava na lavoura de subsistência para complementar a sua alimentação (MOURA, 1989). Havia um déficit de atividade diversionista em decorrência não só da exaustiva semana de trabalho, mas também por ser proibida a realizaçāo de reuniōes entre os escravos. Até a cultuação de seus deuses lhe foi negada, aumentando assim ainda mais a sua angústia espiritual.

Entretanto, mesmo com todos os mecanismos de coação, a escravidão não foi aceita passivamente. $O$ negro resistiu de todas as formas que lhe eram possíveis. Contrapondo-se individualmente através do desenvolvimento de seu potencial de violência, caracterizado pelo suicídio, pelo assassinato ou pelo aborto (SILVA, 1988). Coletivamente, resistiu ao trabalho, realizou fugas, formou quilombos e organizou insurreições (MOURA, 1989).

A escravidão negra foi a relação social de trabalho absoluta em todas as atividades econômicas, em todas as regióes do país. Isto explica não só o maior contingente populacional de negros do mundo, logo após da Nigéria (LOPES et al, 1987), mas também no meu entender uma certa resistência ao trabalho uma vez que este sempre esteve associado na nossa história ao escravo, ao outro, ao não-ser.

Conforme observam LOPES et al (1987) a acumulação de capital no Brasil - preparadora do capitalismo, não foi precedida pelo feudalismo, nem pelo colonialismo, visto que fomos objeto da exploração e não sujeito. Portanto a construção do capitalismo no Brasil foi diferente do capitalismo europeu, conseqüentemente deve ser estudado sob uma perspectiva diferente daquela que explica o capitalismo colonizador. Quatro séculos de escravidão afetaram a saúde da raça negra e de sua descendência. $O$ racismo contra o negro teve naquelas estruturas suas raízes e permanece mesmo com a instituição do trabalho juridicamente livre. Assim sendo, cinco séculos de ideologia da escravidão ainda afetam a saúde do negro e o seu desenvolvimento social, em particular, e da sociedade brasileira como um todo.

\section{A saúde do negro: hoje.}

Pelo o que foi exposto anteriormente, entendo que a saúde, fenômeno multicausal, está para a etnia negra brasileira historicamente determinada em decorrência da sua inserção no sistema capitalista como população escrava, expropriada inclusive de sua condição humana. Em conseqüência da ideologia construída no período escravocrata, há hoje um vazio de pesquisas e estudos na área da saúde referentes a este grupo humano.

A criação de uma linha de pesquisa poderá acontecer a partir da criação de grupos de estudos como, por exemplo, o Grupo de Estudos e Pesquisas sobre as Condiçōes de Saúde do Negro - GESPENE que tem 
por objetivos traçar o perfil da saúde do negro brasileiro; estudar a existência, ou não, de disparidade entre o estado de saúde do negro em relaçāo a de outros grupos étnicos; e correlacionar os resultados destes estudos com outras variáveis (OLIVEIRA; SOUZA, 1990).

$\mathrm{Na}$ falta de um perfil sobre a saúde do negro, faremos neste estudo um paralelo da raça negra com classe social. Em que pese, considerarmos classe social um parâmetro precário por negar ao negro sua identidade cultural, reforçando ainda mais a ideologia da escravidão.

Com o término formal da escravidão e o incremento do imigrantismo, o negro passa a receber pelo trabalho realizado um salário que varia conforme a procura de mão-de-obra no mercado, sendo que o mercado procura para trabalhar pessoas de boa aparência, onde está implícito: cabelos louros, olhos e pele clara (MOURA, 1986; AZEVEDO, 1987).

Obviamente, o salário não cobre todas as necessidades do trabalhador, nem de sua família (não foi por piedade que o capitalismo evoluiu do trabalho escravo para o trabalho livre). Segundo TOMAZI (1986), as necessidades de crianças, velhos e mulheres, por definição não são reconhecidas nos salários. Desta forma, os períodos não-produtivos dos trabalhadores (a infância, a enfermidade, a velhice e o desemprego) não são cobertos pelos salários.

Dentro da classe assalariada, os negros ocupam principalmente as posições de base, não especializadas, e recebem três vezes menos que os brancos, em torno de US\$ 87 (MOURA, 1988). Analisando a saúde das classes sociais, TOMAZI (1986) diz que:

"A extração da mais-valia absoluta caracteriza os setores de produ̧̧ão com pouco desenvolvimento tecnológico, e significa uma combinação de diferentes elementos: custo calórico alto, esforço físico duro e tempo insuficiente de descanso, combinado com um nivel salarial baixo, o que estabelcce limites precisos à reprodução adequada da força de trabalho $e$ acelera ainda mais o desgaste do trabalhador." (p. 26)

Se o escravo vivia em média sete anos, atualmente, segundo Tomazi (1986), quem ganha menos de um salário mínimo tem uma esperança de vida de cinqüenta e cinco, isto sem contar que a mortalidade é mais alta entre os operários não-qualificados.

Pode-se inferir que a discriminação racial (herança dos quatro séculos de uma estrutura escravocrata e dos cinco séculos de ideologia correspondente) é responsável na atualidade pela continuidade das agressōes à saúde dos negros, tornando os seus problemas de saúde crônicos, complexos e, vale ressaltar, desconhecidos para os profissionais que pretendem tratá-los.

A saúde do negro: amanhā.

A estória do negro nos dá condições de afirmar que as perspectivas a curto prazo são sombrias. A médio e longo prazo poderá ocorrer uma 
transformação se o negro pegar as rédeas de sua história e desviar-se da trajetória decadente que lhe foi traçada por uma sociedade construída com base na discriminação racial e de classe.

Pequenas mudanças acontecem isoladamente, mas o verdadeiro problema do negro é um problema político, ideológico, e, portanto, só politicamente será resolvido. Enquanto as instituições sociais não tiverem por objetivo o resgate da imensa dívida social para com os negros, deixada pela escravidão e perpetuada por políticas discriminatórias, pouco avançaremos.

Aos que têm clareza sobre a discriminaçāo racial, cabe a luta para inserir nestas instituições o compromisso pelo desenvolvimento da raça negra.

A criação de um grupo de estudos institucionalizado sobre a saúde do negro, como aconteceu em São Paulo, deve estender-se aos demais estados da federação e demais órgãos públicos responsáveis pela saúde da coletividade e também pelas instituições que desenvolvem pesquisas. Mais do que uma esperança, a formação de grupos institucionais deve ser para os negros em particular, e para a sociedade como um todo, uma meta a ser alcançada.

\section{CONSIDERAÇÕES FINAIS}

Com base na premissa de que o trabalho é um referencial de saúde para as pessoas, considerei que para o negro, em razão da escravatura, o conceito de trabalho interligou-se ao de doença. Com a continuidade da ideologia da escravidão e da exploração de seu trabalho assalariado, o negro nos dias atuais padece dos mesmos problemas de saúde de seus ancestrais escravos, por ter-lhe sido impedido o seu desenvolvimento social.

Utilizei a Taxonomia I da NANDA (NORTH AMERICAN NURSING DIAGNOSIS ASSOCIATION, 1989; CRUZ, para nomear os possíveis diagnósticos de enfermagem para este grupo étnico desde o seu seqüestro em massa na África até os dias atuais. Deste modo, pode-se aquilatar a dimensão dos problemas apresentados por este grupo humano e os cuidados de enfermagem que seriam, e ainda são, necessários para resolvê-los.

A partir das denúncias feitas à estrutura ideológica racista da sociedade juntamente com o trabalho político organizado, espera-se ver surgir organismos institucionais voltados para a saúde do negro em especial.

O estabelecimento de uma política global para o desenvolvimento social do negro brasileiro é, no meu entendimento, fundamental para a recuperação e a manutenção da saúde de toda a coletividade. 
CRUZ, I. C. F. da. The African-Brazilian and health; yesterday, today and tomorrow. Rev.

Esc. Enf. USP., v. 27, n. 3, p. 317-27, dec. 1993.

This study refers to a literature revieu' on the health-disease process in AfricanBrazilian community. The author utilizes the Taxonomy I of nursing diagnoses do point out the possible response patterns to the health problems / vital processes showed by this ethnic group since they were slaves. The African-Brazilian poverty and the insipient number of research papers related to this ethnic group lead the author to concluded that there is a social stratification by race and that urge to create an institucional task force to improve the social development of the African-Brazilian, and to research their health beliefs, practices, and values.

UNITERMS: African-Brazilian, Negro, Nursing Diagnoses.

\section{REFERÊNCIAS BIBLIOGRÁFICAS}

AZEVEDO, C.M.M. de. Onda negra, medo branco: o negro no imaginário das elites século XIX. Rio de Janeiro, Paz e Terra, 1987.

CARDOSO, C.F. et al. Escravidão e abolição no Brasil: novas perspectivas. Rio de Janeiro, Zahar, 1988.

CARPENITO, L.J. Nursing diagnosis: application to clinical practice. 2.ed. Philadelphia, J.B Lippincott, 1987.

CHIAVENATO, J.J. O negro no Brasil: da senzala à guerra do Paraguai. 4.ed. São Paulo, Brasiliense, 1987.

CRUZ, I.C.F. a. Diagnóstico de enfermagem e sua aplicação: revisāo da literatura. Rev.Esc.Enf.USP., v.24, n.1, p.149-62, 1990.

CRUZ, I.C.F. da.; CRUZ, D. de A.L.M. da. Os padrōes de comportamento humano: uma proposta de traduçáo dos termos da Taxonomia I sobre diagnósticos de enfermagem. Rev.Esc.Enf.USP., v.25, n.1, p. 17-20, 1991.

FARIAS,J.N. de. et al. Diagnóstico de enfermagem: uma abordagem conceitual e prática. João Pessoa, Santa Marta, 1990.

FREITAS, D. A luta pela liberdade. In: SĀO PAULO (Estado). Secretaria da Educaçāo. Grupo de trabalho para Assuntos Afro-Brasileiros. Salve 13 de Maio? São Paulo, 1988. p.22-3.

IDE, C.A.C.; CHAVES, E.C. A questão da determinação do processo saúde-doença. Rev.Esc.Enf.USP., v.24, n.1, p.163-7, 1990.

LOPES, H.T. et al. Dimensảo histórico-sociológica do negro. In: NEGRO e Cultura no Brasil. Rio de Janeiro, UNIBRADE/UNESCO, 1987. p.9-24.

MAURo, F. O Brasil no tempo de Dom Pedro II - 1831-1889. São Paulo, Cia. das Letras/Circulo do Livro, 1991. 
MOURA, C. O negro no mercado de trabalho. 2.ed. São Paulo, Conselho de Participação e Desenvolvimento da Comunidade Negra do Estado de São Paulo, 1986.

Estratégia do imobilismo social contra o negro no mercado de trabalho. São Paulo em Perspectiva., v.2, n.2, p.44-6, 1988.

História do negro brasileiro. São Paulo, Ática, 1989.

MURARO, R.M. Sexualidade da mulher brasileira: corpo e classe social no Brasil. Petrópolis, Vozes, 1983.

NORTH AMERICAN NURSING DIAGNOSIS ASSOCIATION. Taxonomy I: revised St.Louis, 1989.

OLIVEIRA, R. de; SOUZA, D de Condiçóes de saúde do negro. São Paulo, 1990/Mimeografado/

PINSKY, J. Mitos da escravidão no Brasil. In: SÃO PAULO (Estado) Secretaria da Educação. Grupo de trabalho para Assuntos Afro-Brasileiros. Salve 13 de Maio? São Paulo, 1988. p.12-3.

QUEIROZ, S.R.R. de. Escravidāo negra no Brasil. São Paulo, Ática, 1987.

SILVA, I.P. da. A resistência negra no mundo dos senhores de escravos. In: SĀO PAULO (Estado) Secretaria da Educação. Grupo de trabalho para Assuntos Afro-Brasileiros. Salva 13 de Maio? São Paulo, 1988, p.11.

SKIDMORE, T.E. Fato e mito: descobrindo um problema racial no Brasil. Cad.Pesq., n.79, p.5-16, 1991.

SOUZA, M.G.F. et al. Brancos descendentes de negros na sociedade brasileira. Ci.e Cult., v.39, n.12, p. 1186-9, 1987.

TOMAZI, Z.T. Saúde e estado brasileiro. São Paulo, Global Editora, 1986. 